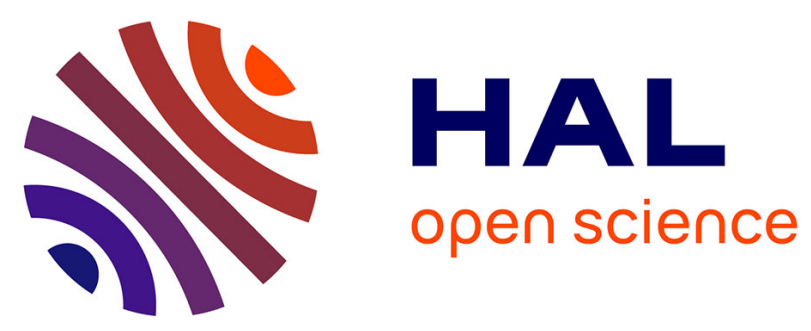

\title{
Spontaneous mutation rate as a source of diversity for improving desirable traits in cultured microalgae
}

Marc Krasovec, Sophie Sanchez-Brosseau, Nigel Grimsley, Gwenael Piganeau

\section{To cite this version:}

Marc Krasovec, Sophie Sanchez-Brosseau, Nigel Grimsley, Gwenael Piganeau. Spontaneous mutation rate as a source of diversity for improving desirable traits in cultured microalgae. Algal Research Biomass, Biofuels and Bioproducts, 2018, 35, pp.85-90. 10.1016/j.algal.2018.08.003 . hal-01957301

\section{HAL Id: hal-01957301 https://hal.sorbonne-universite.fr/hal-01957301}

Submitted on 17 Dec 2018

HAL is a multi-disciplinary open access archive for the deposit and dissemination of scientific research documents, whether they are published or not. The documents may come from teaching and research institutions in France or abroad, or from public or private research centers.
L'archive ouverte pluridisciplinaire HAL, est destinée au dépôt et à la diffusion de documents scientifiques de niveau recherche, publiés ou non, émanant des établissements d'enseignement et de recherche français ou étrangers, des laboratoires publics ou privés. 


\title{
Spontaneous mutation rate as a source of diversity for improving desirable traits in cultured microalgae
}

\author{
Marc Krasovec $^{1}$, Sophie Sanchez-Brosseau, Nigel Grimsley, Gwenael Piganeau* \\ Sorbonne Universités, UPMC Univ Paris 06, CNRS, Biologie Intégrative des Organismes Marins (BIOM), Observatoire Océanologique, F-66650 Banyuls/Mer, France
}

Keywords:

Mutation rate

Mutation accumulation

Green algae biotechnology

Picochlorum

Domestication

\begin{abstract}
A B S T R A C T
Mutations are the main origin of the biodiversity and biological innovations across the tree of life. The number of mutations in a population depends of the mutation rate, noted $\mu$, a key parameter for understanding the evolutionary and adaptive capacity of a species. New mutations are submitted to selection and drift and their probability of fixation in a population depends on their advantageous, deleterious or neutral fitness effect. This process occurs in natural populations, but also in any lab cultures. In this context, the role of spontaneous mutations in the generation of genetic diversity in cultured algae has so far been overlooked, despite its influence on the acquisition and maintenance of desirable phenotypic traits. Several algal species that have a high biotechnological potential, such those producing high-value molecules, might be improved by domestication and oriented selection by experimental evolution. Here, we provide the first estimation of the spontaneous mutation rate, $\mu$, in Picochlorum costavermella (Trebouxiophyceae), a green alga with many potential biotechnological applications. Its spontaneous mutation rate is $\mu=10.12 \times 10^{-10}$ (CI Poisson distribution, $\mu=6.3-15.4 \times 10^{-10}$ ) mutations per nucleotide per genome per generation. This is one of the highest mutation rates reported for a unicellular eukaryote.
\end{abstract}

\section{Introduction}

Natural selection enables species to adapt from standing genetic variation, powered by new mutations, which constitute the main source of genetic diversity in a population. Quantifying the rate of mutations and their effects is thus of primary importance to better understand the evolution and adaptive potential of a species. Beyond the evolutionary importance of mutations, generation of genetic diversity is also relevant for the domestication process, as one single mutation can trigger a novel trait of interest in a species [1]. Domestication of crops and animals began several thousand years ago and involved manual selection and breeding for thousands of generations [2,3] and more recently genetic engineering [4]. In contrast to domesticated macro-organisms, which have long generation times, obligate sexual reproduction, and small population sizes, microorganisms have short generation times, asexual reproduction and huge population sizes. As a consequence, rare events, like spontaneous mutations, can be observed and monitored within a short time lag, typically within a few months in microbial cultures [5]. In the context of the global challenge caused by the scarcity of natural resources, the domestication of novel species and the development of biotechnologies are evoked as promising strategies [6].
Green microalgae have been brought into the spotlight as favoured candidates for biotechnological development [7]. Among other advantages, they have a short asexual life cycle, many can be grown in marine water, many are transformable and their biotechnological potential is manifold such as the production of biofuels [8-13], the production of proteins and high value molecules for health food or cosmetics [14-16], the production of hydrogen [17], and their photosynthetic production can be optimized [18].

Phenotypic traits of interest may be further increased by experimental evolution [19] and directional selection of algal strains for biotechnological applications. Any natural population harbours a standing genetic diversity [20], which enables adaptation to environmental changes and selection pressures. Traits of interest may be selected from this standing genetic diversity, but very little data about natural diversity in microalga is available yet $[21,22]$. Alternatively, adaptation may also occur from new mutations. Domestication of land plants revealed several cases in which one single nucleotide mutation induced the trait of interest ([23] for a review). The estimation of the spontaneous mutation rates is paramount for investigating the possibility of generating phenotypic trait of interest by mutations. The probability of obtaining a desirable genotype may be also increased by

\footnotetext{
* Corresponding author.

E-mail address: gwenael.piganeau@obs-banyuls.fr (G. Piganeau).

${ }^{1}$ Present address: Department of Plant Sciences, University of Oxford, South Parks Road, Oxford OX1 3RB, United Kingdom.
} 
mutagenesis. Different protocols have been developed, such as heavyion irradiation in Parachlorella kessleri [24] and Desmodesmus spp. [25], gamma rays in Chlorella spp. [26,27] or UV irradiation in Chlorella sorokiniana [28,29]. However, mutagenesis has three pitfalls. First, it dramatically increases the deleterious mutation load. Algal populations must therefore be carefully exposed to a mutagen in order to not compromise their survival capacity. In the case of ultraviolet (UV) irradiation, the survival rate may reach only $10 \%$ in Chlorella sorokiniana $[28,29]$. Second, it indirectly selects for cells resistant to the mutagenic factor. Third, microorganisms derived from chemical or radiation mutagenesis are included under the Genetically Modified Organisms umbrella and are therefore submitted to many commercial and political conditions [30].

The spontaneous mutation rate of any organisms can be estimated by mutation accumulation (MA) experiments, and this ideally requires a high quality reference genome sequence [31-33]. The development of high throughput genome sequencing technologies led to a significant improvement in the practicability of whole genome sequencing, mirrored in an increase in the number of available complete and annotated reference genomes in microalga in the last decade [34]. The principle of MA experiment is to monitor genetic changes in MA lines maintained at a low population size by serial bottlenecks [35], as effective population size is inversely proportional to the strength of selection. Thus, a very low $N_{e}$ drastically limits the efficiency of selection, allowing as many spontaneous mutations as possible to become fixed, including the deleterious ones, in order to estimate to the total number of spontaneous mutations [36]. These events are identified by comparing the MA genomes to the ancestral genome sequence. The monitoring of the number of cell divisions throughout the experiment is required to estimate the mutation rate per cell division. Mutation accumulation approaches have been applied to a large range of species, including bacteria and eukaryotes [32]. In green algae, MA studies have been conducted in a few model species and have allowed the fitness effects of mutations $[5,37,38]$ and spontaneous mutation rates to be estimated in Chlamydomonas reinhardtii [39-41] and four Mamiellophyceae species; Micromonas commoda RCC299, Bathycoccus prasinos RCC1105, Ostreococcus mediterraneus RCC2590, and O. tauri RCC4221 [42].

In this study, we exemplify use of a mutation accumulation experiment in Picochlorum RCC4223, a green algal species of the Trebouxiophyceae class (Chlorophyta) [43]. We used the same protocol as previously described [5], where all cultures are maintained in liquid medium and cell count is estimated by flow cytometry. Picochlorum RCC4223 has a small haploid genome of $\sim 13.5 \mathrm{Mb}$ with $79.5 \%$ of coding sequences and $46 \%$ GC content [44]. Strains from the genus Picochlorum are versatile algae for large-scale culturing, capable of growing in a wide range of salinities and temperatures $[45,46]$ with a few completely sequenced genomes already available, including the strain RCC4223 [46,47]. They also constitute interesting models in different fields, such as medicine [48], biofuels [49], food and aquaculture $[50,51]$ and production of high value molecules [52].

\section{Materials and methods}

\subsection{Mutation accumulation (MA) experiment}

The Picochlorum costavermella RCC4223 strain was isolated from an estuary of the river "La Massane" $\left(42^{\circ} 32^{\prime} 36 \mathrm{~N}, 3^{\circ} 03^{\prime} 09 \mathrm{E}\right.$, France) and has been deposited in the Roscoff Culture Collection [53] (http:// roscoff-culture-collection.org/).

Twelve MA lines were kept from a clonal ancestral population in 24well plates, at $20^{\circ} \mathrm{C}$ with a light cycle of $16 \mathrm{~h}-8 \mathrm{~h}$ dark-light in L1 medium. MA lines were inoculated as single cells after endpoint dilution and maintained by serial one-cell bottlenecks every 14 days, as described in [5]. At each bottleneck, cell concentration was measured with a FACSCanto II flow cytometer (Becton Dickinson, Franklin Lakes, NJ, U.S.A.) using natural chlorophyll fluorescence $(670 \mathrm{~nm}$ used FL3 data) and SSC acquisitions. Effective population size, $N_{e}$, was estimated with the harmonic mean of cell number between bottlenecks and the number of generations (number of cell divisions) being provided by the following equation:

$d=e^{\left[\ln \left(\frac{N_{t}}{N_{0}}\right) / t\right]}$

where $N_{t}$ is the total number of cells measured by flow cytometry, and $t$ the time between two bottlenecks, i.e 14 days. Lines were maintained for 199 days and went through a series of 14 bottlenecks.

\subsection{Sequencing and mutations identification}

We extracted DNA using a CTAB protocol [54] and sequenced by Illumina MiSeq (200 bp paired-end reads) performed by GATC biotech ${ }^{\circledR}$ (Konstanz, Germany). Twelve MA lines and the ancestral type were sequenced. MiSeq reads were aligned to the reference genome with BWA mem [55], bam files were treated with SAMtools [56] and mutations were called with GATK HaplotypeCaller [57]. Afterwards, final $v c f$ files and candidate mutations were obtained after following filtered steps: removal of low mapping quality sites (MQ < 40), low covered sites (DP < 10) and candidates shared by two MA lines. SnpEff program [58] permitted synonymous, non-synonymous, intronic and intergenic mutations to be identified using the annotation available on the ORCAE web site [59]. This mutation calling pipeline was used for base-substitution and insertions-deletions (indels).

The mutation rate was calculated by dividing the total number of $d e$ novo mutations by the total generations and the callable genome size to give the mutation rate per nucleotide per genome per generation $(\mu)$. The mutation rate per genome per generation is given by $U=G \times \mu$, where $G$ is the genome size.

Raw data are available in GenBank with Bioproject accessions PRJNA453760 and PRJNA389600 (Table S1).

\subsection{Mutation spectrum}

Pearson's chi-squared was used to test the distribution of observed mutations with the expected distribution, $H_{O}$, assuming that mutations appear randomly and independently in the genome. We compared the distribution of mutations between coding and non-coding regions; the level of expression of mutated sites using STAR [60]; the synonymous and non-synonymous base-substitution mutations; the direction of mutations from each nucleotide to others and the nucleotide context (between 2 and 10 nucleotides) around mutated sites.

The substitution spectrum between the 4 nucleotides is usually biased, and several previous studies have reported a bias from GC to AT mutations as compared to AT to GC mutations. This mutation bias has a consequence on the equilibrium GC content of the genome, noted $G C_{e q}$, which would be reached if the GC composition was the consequence of mutation processes alone. At equilibrium GC content, the number of mutations from GC to AT equals the number of mutations from AT to GC. The $G C_{e q}$ can be estimated from the following equations [61]:

$R_{1}=\frac{(\mathrm{GC} \rightarrow \mathrm{AT})}{G C_{n}}, \quad R_{2}=\frac{(\mathrm{AT} \rightarrow \mathrm{GC})}{A T_{n}}, \quad G C e q=\frac{R_{2}}{R_{1}+R_{2}}$,

where $G C_{n}$ and $A T_{n}$ are the total GC and AT nucleotides of the genome; $G C \rightarrow A T$ and $A T \rightarrow G C$ are the number of de novo mutations.

\section{Results and discussion}

\subsection{Mutational spectrum}

The experiment lasted 199 days, corresponding to an average of 133 generations per MA line with an average effective population size of $N_{e}$ $\sim 6$. In silico analysis identified a total of 21 new mutations in the $12 \mathrm{MA}$ lines: 19 base-substitutions and 2 insertion-deletions (indels) (Table 1). 
Table 1

Distribution of de novo mutations between MA lines. BS and ID are the basesubstitution and insertion-deletion mutations. $G^{*}$ corresponds to the genome percentage used for identification of mutations. ML is the initial line of the mutation accumulation experiment.

\begin{tabular}{llllll}
\hline MA lines & $G^{*}(\%)$ & Coverage & BS & ID & Generations \\
\hline ML & 98.9 & 10.4 & - & - & - \\
1 & 97.2 & 24.1 & 1 & 0 & 143 \\
2 & 97.1 & 29.8 & 2 & 0 & 148 \\
3 & 97.2 & 17.0 & 0 & 0 & 120 \\
4 & 97.1 & 20.0 & 1 & 0 & 125 \\
5 & 97.1 & 23.7 & 0 & 0 & 123 \\
6 & 97.3 & 22.2 & 6 & 0 & 128 \\
7 & 97.7 & 11.1 & 1 & 0 & 90 \\
8 & 96.9 & 39.5 & 1 & 0 & 134 \\
9 & 97.2 & 7.4 & 0 & 0 & 145 \\
10 & 97.2 & 12.1 & 5 & 1 & 156 \\
11 & 98.1 & 18.6 & 1 & 0 & 130 \\
12 & 97.2 & 29.8 & 0 & 1 & 153 \\
\hline
\end{tabular}

All predicted mutations were validated by PCR and Sanger re-sequencing.

About $\sim 97.3 \%$ of the genome was used for identification of mutations (Table 1), excluding a possible bias from a variation of the number of callable sites between MA lines and a possible bias due to a variation of the mutation rate within the genome. Because mutations are rare events, we assume that they follow a Poisson distribution. If the data do not follow a Poisson distribution, as in this study (Chi-Square, $P$ value $<0.01$ ), the molecular clock is considered as over-dispersed. This variation in mutation rates between MA lines might come, first, from the limited time period of the experiment and the low number of MA lines, and second from the possible stochastic production of DNA repair proteins such as reported in Escherichia coli [62]. This is perhaps responsible of an increase of mutation rate in some MA lines, increasing the global mutation rate in the whole experiment.

\subsection{Mutation rate per nucleotide per cell division in Picochlorum}

Picochlorum costavermella RCC4223 has one of the highest spontaneous mutation rates estimated for a unicellular eukaryote (Table 2). Considering all MA lines, $\mu_{\mathrm{bs}}$, the base-substitution mutations per nucleotide rate, is $9.19 \times 10^{-10}$ (Poisson distribution CI 95\%; $\left.5.53 \times 10^{-10}-1.44 \times 10^{-09}\right)$, and $\mu_{\mathrm{ID}}$, the indels mutation rate per nucleotide, is $9.64 \times 10^{-11}$ (Poisson distribution CI 95\%; $1.17 \times 10^{-11}-3.48 \times 10^{-10}$ ). This gives a total mutation rate $\mu$ of

Table 2

Spontaneous mutation rate in unicellular eukaryotes. $\mu$ is the mutation rate per nucleotide per generation and $U$ is the number of mutations per genome per generation, $G$ is the nuclear genome size and $G^{*}$ the percentage of genome encoding for protein coding genes.

\begin{tabular}{llllll}
\hline Species & $\mu^{-10}$ & $U$ & $G(\mathrm{Mb})$ & $G^{*}(\%)$ & References \\
\hline Chlorophyta & & & & & \\
$\quad$ Picochlorum costavermella & 10.12 & 0.0132 & 13.5 & 80 & This study \\
$\quad$ Micromonas pusilla & 9.76 & 0.0205 & 21.1 & 82 & {$[42]$} \\
$\quad$ Ostreococcus mediterraneus & 5.92 & 0.0081 & 13.5 & 84 & {$[42]$} \\
$\quad$ Ostreococcus tauri & 4.79 & 0.0062 & 13.0 & 82 & {$[42]$} \\
$\quad$ Bathycoccus prasinos & 4.39 & 0.0066 & 15.1 & 83 & {$[42]$} \\
$\quad$ Chlamydomonas reinhardtii & 3.23 & 0.0362 & 122.0 & 17 & {$[40]$} \\
Yeast & & & & & \\
$\quad$ Saccharomyces cerevisiae & 3.30 & 0.0041 & 12.3 & 71 & {$[65]$} \\
$\quad$ Rhodotorula toruloides & 1.90 & 0.0039 & 20.5 & 63 & {$[66]$} \\
$\quad$ Schizoaccharomyces pombe & 1.70 & 0.0021 & 12.6 & 55 & {$[64]$} \\
Ciliates & & & & & \\
$\quad$ Paramecium tetraurelia & 0.19 & 0.0014 & 72.1 & 78 & {$[67]$} \\
$\quad$ Dictyostelium discoideum & 0.29 & 0.0010 & 34.1 & 62 & {$[68]$} \\
$\quad$ Tetrahymena thermophila & 0.076 & 0.0008 & 130.3 & 38 & {$[69]$}
\end{tabular}

$1.012 \times 10^{-9}$ mutations per nucleotide per generation, assuming that a generation in that species is one cell division or one population division. The corresponding mutation rates per genome, noted $U$, are $U_{b s}=0.0119$ base-substitution mutations and $U_{I D}=0.0013$ insertionsdeletions per genome per generation, corresponding to a total mutation rate $U_{\text {tot }}=0.0132$ mutations per genome per generation.

Although a high mutation rate predicts that new mutations will accumulate quickly, including advantageous mutations, it also increases deleterious mutation events. In accordance with some previous MA studies [63], the fitness of the MA lines decreased significantly during the experiment (Pearson linear model, $\rho=-0.36, P$ value $=1.7 \times 10^{-6}$ ), indicating that some deleterious mutations have been fixed in MA lines. However, mutation effects are environmentdependent so that a deleterious mutation in one condition is not necessarily deleterious in another, as previously demonstrated in Mamiellophyceae green algae [5].

Mutation rate variation at the intra-specific level, as observed in $C$. reinhardtii [39] and other classical models [64] suggests that mutation rate estimates may not necessarily be extrapolated to phylogenetically closely related species and strains. Thus, the mutation rate estimated in RCC4223 may not be generalized to other Picochlorum strains.

\subsection{Mutations distribution in the genome}

Because of the redundancy of the genetic code and the assumption that selection is stronger against non-synonymous mutations, we tested whether we could detect some evidence of selection in our experiment by estimating the ratio of synonymous versus non-synonymous mutations in coding sequences. In the absence of selection, we expect the mutation rate to be equal in non-synonymous and synonymous positions as there are one-third of synonymous positions (the last position of the codon) and two-third non-synonymous positions (the two first positions of the codon) in coding sequences. The observed proportion was as expected under neutral evolution (Table 3), consistent with the lack of selection against non-synonymous mutations.

$R_{1}$ (GC $\rightarrow$ AT mutation rate) and $R_{2}$ (AT $\rightarrow$ GC mutation rate) are respectively equal to $9.61 \times 10^{-10}$ and $4.12 \times 10^{-10}$ mutations per nucleotide per generation. The expected $G C_{e q}$ is $\sim 30 \%$, while the observed GC content is $46 \%$. Using $R_{1}$ and $R_{2}$, we are able to calculate the mutation rate at $G C_{e q}$. Because $R_{1}>R_{2}$, the deviation from $G C_{e q}$ is responsible of a modest increase of $\sim 9 \%$ of the mutation rate in this strain. This deviation is known to influence the inter-specific mutation

Table 3

The distribution of the de novo mutations in the genome, predicted using the program SnpEFF [58].

\begin{tabular}{lllll}
\hline Contig & Position & Reference & Mutation & Effect \\
\hline 1 & $1,412,265$ & A & G & Synonymous coding \\
2 & $1,558,965$ & T & A & Non synonymous coding \\
3 & $1,431,057$ & G & A & Intergenic \\
3 & $1,438,974$ & C & T & Synonymous coding \\
4 & 388,329 & G & T & Intergenic \\
4 & 532,113 & C & A & Non synonymous coding \\
4 & 632,871 & A & G & Non synonymous coding \\
4 & 726,437 & T & A & Non synonymous coding \\
4 & 934,361 & C & A & Intergenic \\
6 & 671,466 & G & A & Non synonymous coding \\
10 & 496,542 & C & G & Non synonymous coding \\
10 & 615,708 & A & T & Intergenic \\
12 & 132,864 & T & C & Intergenic \\
12 & 160,261 & C & T & Synonymous coding \\
12 & 545,145 & T & C & Intergenic \\
13 & 215,260 & G & A & Non synonymous coding \\
13 & 240,891 & G & C & Non synonymous coding \\
13 & 475,120 & C & G & Intergenic \\
41 & 2537 & A & C & Non synonymous coding \\
27 & 93,213 & TG & T & Frame shift \\
13 & 8595 & T & TTA & Frame shift \\
& & & & \\
\hline & & & & \\
\hline
\end{tabular}


rate variation [42]. Compared to other green algal models, the GC deviation increases the mutation rate by $\sim 12 \%$ in $O$. tauri [42] and $\sim 43 \%$ in C. reinhardtii [42].

\subsection{Biotechnological implications of spontaneous mutation rates}

The spontaneous mutation rate determines the number of mutations arising in a culture of microalgae per generation. We can thus estimate the number of mutations in a Picochlorum RCC4223 culture, starting from an inoculum of $N_{O}=10$ cells maintained for 30 days, assuming one cell division per day and adequate provision of nutrients and light. According to these simple assumptions, this will lead to a culture of $2^{30}$ cells $\left(\sim 5.4 \times 10^{9}\right.$ cells $)$ in 1 Litre of culture. The number of mutations per genome per generation $U=0.0132$ implies this culture harbours $\sim 3.57 \times 10^{7}$ mutant cells $\left(3.54 \times 10^{7}\right.$ cells with one mutation, $23.4 \times 10^{4}$ cells with 2 mutations, 1543 cells with 3 mutations and 10 cells with 4 mutations), provided that none of the spontaneous mutations were lethal. This calculation suggests that the number of mutants generated spontaneously is substantial and increases linearly with the spontaneous mutation rate and the number of cells in the culture. Furthermore, the spontaneous mutation rate we have estimated does not account for polymorphism due to transposable elements [70], or large scale genome rearrangements [21].

Therefore, strains with higher $U$ and high cell concentration will enable the highest number of mutants to be reached in a given volume of culture. However, as a consequence of the large variation of genome sizes between eukaryotes, the proportion of spontaneous mutations occurring within protein coding regions may vary from 17 to $84 \%$ (Table 2). To account for this variation, Sung et al. [71] suggested estimating the mutation rate on the sum of protein-coding DNA, coined the effective genome size.

The question remains whether this spontaneous genetic variation is sufficient for experimental evolution, and this relies on an efficient selection procedure for isolating mutants with the trait of interest. Many different selection protocols have already been developed for microalgae. The most straightforward is phenotypic selection for growth rate, in which cells are continuously maintained in an actively growing state such that adaptive variants with faster division rate can get fixed in the population (there is no bottleneck). Such selection is highly efficient in bacteria (e.g in Escherichia coli $[72,73]$ ) and has also been applied to microalgae. For example, experimental evolution with a high effective population size induces an increase of $35 \%$ in the growth rate after 1880 generations without the use of mutagens in Chlamydomonas reinhardtii [74], where cultures fixed 149 mutations in total. Within the class Mamiellophyceae, several evolved lines showed higher growth rates than the ancestral type in a wide range of salinities or upon exposure to herbicides [5]. An obvious limit to this selection strategy is when the phenotypic trait of interest is not tied to the growth rate. An alternative selection strategy is single cell sorting flow cytometry if the phenotypic trait of interest can be tied to the size or the fluorescence of microalga [75]. For example, cells with higher lipid content may be isolated out of a population by using fluorescent dyes such as Nile red and BODIPY 505/515 [76,77]. Another very promising fast developing strategy is the use of microfluidic devices that enable the screen and isolation of single cells, and thus their individual phenotypic screen [78].

Here, we provide the first estimate of the mutation rate of Picochlorum costavermella RCC4223 and show that it is high enough to assure the apparition of $\sim 35$ million variants within 30 days in a standard culture starting with a modest inoculum of 10 cells. We argue that in many microalga, the use of mutagenesis processes may not be necessary to generate genetic variation in a culture. It is therefore important that more estimates of spontaneous mutation rates are obtained in microalga of biotechnological interest. Algae with naturally high mutation rates, such as the strain RRC4223, for which several potential biotechnological applications have been documented [43-51], may constitute the best candidates for domestication.

Supplementary data to this article can be found online at https:// doi.org/10.1016/j.algal.2018.08.003.

\section{Acknowledgements}

We are grateful to Sebastien Peuchet, Aurelien De Jode, Claire Hemon and Elodie Desgranges for technical assistance with the mutation accumulation experiment. We acknowledge the Genomics of Phytoplankton lab and the Picochlorum costavermella genome consortium for support and stimulating discussions. We are grateful to the Genotoul bioinformatic platform (INRA) for providing access to the computer cluster.

\section{Declarations of conflict of interest}

None.

No conflicts, informed consent, human or animal rights applicable.

All authors agree to authorship and submission of the manuscript for peer review.

\section{Funding}

This work was funded by ANRJCJC-SVSE6-2013-0005 to GP and SSB, the CNRS and the Ecole Doctorale Complexité du Vivant (ED515, Sorbonne Universités).

\section{Authors' contribution}

GP, SSB and NG conceived the experiment and performed the MA experiment, MK performed DNA extractions, bioinformatic analysis of MA lines, PCR confirmation of candidate SNPs. All authors contributed to the manuscript writing.

\section{References}

[1] W. Wu, X. Liu, M. Wang, R.S. Meyer, X. Luo, M.-N. Ndjiondjop, L. Tan, J. Zhang, J. Wu, H. Cai, C. Sun, X. Wang, R.A. Wing, Z. Zhu, A single-nucleotide polymorphism causes smaller grain size and loss of seed shattering during African rice domestication, Nat. Plants 3 (2017) 17064, https://doi.org/10.1038/nplants. 2017.64.

[2] T. Izawa, The process of Rice domestication: a new model based on recent data, Rice 1 (2008) 127-134, https://doi.org/10.1007/s12284-008-9014-7.

[3] P. Civáň, T.A. Brown, Origin of rice (Oryza sativa L.) domestication genes, Genet. Resour. Crop. Evol. 64 (2017) 1125-1132, https://doi.org/10.1007/s10722-017. 0518-0.

[4] J.R. Prado, G. Segers, T. Voelker, D. Carson, R. Dobert, J. Phillips, K. Cook, C. Cornejo, J. Monken, L. Grapes, T. Reynolds, S. Martino-Catt, Genetically engineered crops: from idea to product, Annu. Rev. Plant Biol. 65 (2014) 769-790, https://doi.org/10.1146/annurev-arplant-050213-040039.

[5] M. Krasovec, A. Eyre-Walker, N. Grimsley, C. Salmeron, D. Pecqueur, G. Piganeau, S. Sanchez-Ferandin, Fitness effects of spontaneous mutations in picoeukaryotic marine green algae, G3 Genes Genomes Genet. 6 (2016) 2063-2071, https://doi. org/10.1534/g3.116.029769.

[6] S.P. Carroll, P.S. Jørgensen, M.T. Kinnison, C.T. Bergstrom, R.F. Denison, P. Gluckman, T.B. Smith, S.Y. Strauss, B.E. Tabashnik, Applying evolutionary biology to address global challenges, Science 346 (2014) 1245993, https://doi.org/ 10.1126/science.1245993.

[7] J. de la Noue, N. de Pauw, The potential of microalgal biotechnology: a review of production and uses of microalgae, Biotechnol. Adv. 6 (1988) 725-770.

[8] L. Brennan, P. Owende, Biofuels from microalgae-a review of technologies for production, processing, and extractions of biofuels and co-products, Renew. Sust. Energ. Rev. 14 (2010) 557-577, https://doi.org/10.1016/j.rser.2009.10.009.

[9] Y. Chisti, Biodiesel from microalgae, Biotechnol. Adv. 25 (2007) 294-306, https:// doi.org/10.1016/j.biotechadv.2007.02.001.

[10] T.M. Mata, A.A. Martins, N.S. Caetano, Microalgae for biodiesel production and other applications: a review, Renew. Sust. Energ. Rev. 14 (2010) 217-232, https:// doi.org/10.1016/j.rser.2009.07.020.

[11] A.W.D. Larkum, I.L. Ross, O. Kruse, B. Hankamer, Selection, breeding and engineering of microalgae for bioenergy and biofuel production, Trends Biotechnol. 30 (2012) 198-205, https://doi.org/10.1016/j.tibtech.2011.11.003.

[12] J.B. Shurin, M.D. Burkart, S.P. Mayfield, V.H. Smith, J.B. Shurin, M.D. Burkart, S.P. Mayfield, V.H. Smith, Recent progress and future challenges in algal biofuel production, F1000 Res. 5 (2016), https://doi.org/10.12688/f1000research.9217.1.

[13] E. Stephens, I.L. Ross, J.H. Mussgnug, L.D. Wagner, M.A. Borowitzka, C. Posten, 
O. Kruse, B. Hankamer, Future prospects of microalgal biofuel production systems, Trends Plant Sci. 15 (2010) 554-564, https://doi.org/10.1016/j.tplants.2010.06, 003.

[14] E.W. Becker, Micro-algae as a source of protein, Biotechnol. Adv. 25 (2007) 207-210, https://doi.org/10.1016/j.biotechadv.2006.11.002.

[15] A. Ben-Amotz, M. Avron, The biotechnology of cultivating the halotolerant algaDunaliella, Trends Biotechnol. 8 (1990) 121-126, https://doi.org/10.1016/ 0167-7799(90)90152-N.

[16] R. Raja, S. Hemaiswarya, R. Rengasamy, Exploitation of Dunaliella for beta-carotene production, Appl. Microbiol. Biotechnol. 74 (2007) 517-523, https://doi.org/ 10.1007/s00253-006-0777-8.

[17] M.L. Ghirardi, L. Zhang, J.W. Lee, T. Flynn, M. Seibert, E. Greenbaum, A. Melis, Microalgae: a green source of renewable H2, Trends Biotechnol. 18 (2000) 506-511, https://doi.org/10.1016/S0167-7799(00)01511-0.

[18] P.G. Stephenson, C.M. Moore, M.J. Terry, M.V. Zubkov, T.S. Bibby, Improving photosynthesis for algal biofuels: toward a green revolution, Trends Biotechnol. 29 (2011) 615-623, https://doi.org/10.1016/j.tibtech.2011.06.005.

[19] T.J. Kawecki, R.E. Lenski, D. Ebert, B. Hollis, I. Olivieri, M.C. Whitlock, Experimental evolution, Trends Ecol. Evol. 27 (2012) 547-560, https://doi.org/10. 1016/j.tree.2012.06.001.

[20] R.D.H. Barrett, D. Schluter, Adaptation from standing genetic variation, Trends Ecol. Evol. 23 (2008) 38-44, https://doi.org/10.1016/j.tree.2007.09.008.

[21] R. Blanc-Mathieu, M. Krasovec, M. Hebrard, S. Yau, E. Desgranges, J. Martin, W. Schackwitz, A. Kuo, G. Salin, C. Donnadieu, Y. Desdevises, S. Sanchez-Ferandin, H. Moreau, E. Rivals, I.V. Grigoriev, N. Grimsley, A. Eyre-Walker, G. Piganeau, Population genomics of picophytoplankton unveils novel chromosome hypervariability, Sci. Adv. 3 (2017) e1700239, , https://doi.org/10.1126/sciadv. 1700239.

[22] H. Jang, I.M. Ehrenreich, Genome-wide characterization of genetic variation in the unicellular, green alga Chlamydomonas reinhardtii, PLoS One 7 (2012) e41307, https://doi.org/10.1371/journal.pone.0041307.

[23] T. Sang, Genes and mutations underlying domestication transitions in grasses, Plant Physiol. 149 (2009) 63-70, https://doi.org/10.1104/pp.108.128827.

[24] S. Ota, T. Matsuda, T. Takeshita, T. Yamazaki, Y. Kazama, T. Abe, S. Kawano, Phenotypic spectrum of Parachlorella kessleri (Chlorophyta) mutants produced by heavy-ion irradiation, Bioresour. Technol. 149 (2013) 432-438, https://doi.org/10. 1016/j.biortech.2013.09.079.

[25] G. Hu, Y. Fan, L. Zhang, C. Yuan, J. Wang, W. Li, Q. Hu, F. Li, Enhanced lipid productivity and photosynthesis efficiency in a desmodesmus sp. mutant induced by heavy carbon ions, PLoS One 8 (2013) e60700, https://doi.org/10.1371/journal. pone.0060700.

[26] J. Cheng, H. Lu, Y. Huang, K. Li, R. Huang, J. Zhou, K. Cen, Enhancing growth rate and lipid yield of Chlorella with nuclear irradiation under high salt and $\mathrm{CO} 2$ stress, Bioresour. Technol. 203 (2016) 220-227, https://doi.org/10.1016/j.biortech.2015. 12.032 .

[27] J. Cheng, Y. Huang, J. Feng, J. Sun, J. Zhou, K. Cen, Mutate Chlorella sp. by nuclear irradiation to fix high concentrations of CO2, Bioresour. Technol. 136 (2013) 496-501, https://doi.org/10.1016/j.biortech.2013.03.072.

[28] S. Cazzaniga, L. Dall'Osto, J. Szaub, L. Scibilia, M. Ballottari, S. Purton, R. Bassi, Domestication of the green alga Chlorella sorokiniana: reduction of antenna size improves light-use efficiency in a photobioreactor, Biotechnol. Biofuels 7 (2014) 157, https://doi.org/10.1186/s13068-014-0157-z.

[29] S. Vonlanthen, D. Dauvillée, S. Purton, Evaluation of novel starch-deficient mutants of Chlorella sorokiniana for hyper-accumulation of lipids, Algal Res. 12 (2015) 109-118, https://doi.org/10.1016/j.algal.2015.08.008.

[30] A. Spicer, A. Molnar, Gene editing of microalgae: scientific progress and regulatory challenges in Europe, Biology 7 (2018), https://doi.org/10.3390/biology7010021.

[31] D.L. Halligan, P.D. Keightley, Spontaneous mutation accumulation studies in evolutionary genetics, Annu. Rev. Ecol. Evol. Syst. 40 (2009) 151-172, https://doi.org/ 10.1146/annurev.ecolsys.39.110707.173437.

[32] M. Lynch, M.S. Ackerman, J.-F. Gout, H. Long, W. Sung, W.K. Thomas, P.L. Foster, Genetic drift, selection and the evolution of the mutation rate, Nat. Rev. Genet. 17 (2016) 704-714, https://doi.org/10.1038/nrg.2016.104.

[33] W. Wei, L.-W. Ning, Y.-N. Ye, S.-J. Li, H.-Q. Zhou, J. Huang, F.-B. Guo, SMAL: a resource of spontaneous mutation accumulation lines, Mol. Biol. Evol. 31 (2014) 1302-1308, https://doi.org/10.1093/molbev/msu073.

[34] K. Vandepoele, M. Van Bel, G. Richard, S. Van Landeghem, B. Verhelst, H. Moreau, Y. Van de Peer, N. Grimsley, G. Piganeau, pico-PLAZA, a genome database of microbial photosynthetic eukaryotes, Environ. Microbiol. 15 (2013) 2147-2153, https://doi.org/10.1111/1462-2920.12174.

[35] M. Nei, T. Maruyama, R. Chakraborty, The bottleneck effect and genetic variability in populations, Evolution 29 (1975) 1-10, https://doi.org/10.2307/2407137.

[36] S.F. Elena, R.E. Lenski, Evolution experiments with microorganisms: the dynamics and genetic bases of adaptation, Nat. Rev. Genet. 4 (2003) 457-469, https://doi. org/10.1038/nrg1088.

[37] S.A. Kraemer, A.D. Morgan, R.W. Ness, P.D. Keightley, N. Colegrave, Fitness effects of new mutations in Chlamydomonas reinhardtii across two stress gradients, J. Evol. Biol. (2015), https://doi.org/10.1111/jeb.12807.

[38] A.D. Morgan, R.W. Ness, P.D. Keightley, N. Colegrave, Spontaneous mutation accumulation in multiple strains of the green alga, Chlamydomonas Reinhardtii, Evolution 68 (2014) 2589-2602, https://doi.org/10.1111/evo.12448.

[39] R.W. Ness, A.D. Morgan, R.B. Vasanthakrishnan, N. Colegrave, P.D. Keightley, Extensive de novo mutation rate variation between individuals and across the genome of Chlamydomonas reinhardtii, Genome Res. 25 (2015) 1739-1749, https://doi.org/10.1101/gr.191494.115.

[40] R.W. Ness, A.D. Morgan, N. Colegrave, P.D. Keightley, R.W. Ness, A.D. Morgan,
N. Colegrave, P.D. Keightley, Estimate of the spontaneous mutation rate in Chlamydomonas reinhardtii, Genetics 192 (2012) 1447-1454, https://doi.org/10. 1534/genetics.112.145078.

[41] W. Sung, M.S. Ackerman, S.F. Miller, T.G. Doak, M. Lynch, Drift-barrier hypothesis and mutation-rate evolution, Proc. Natl. Acad. Sci. U. S. A. 109 (2012) 18488-18492, https://doi.org/10.1073/pnas.1216223109.

[42] M. Krasovec, A. Eyre-Walker, S. Sanchez-Ferandin, G. Piganeau, Spontaneous mutation rate in the smallest photosynthetic eukaryotes, Mol. Biol. Evol. 34 (2017) 1770-1779, https://doi.org/10.1093/molbev/msx119.

[43] W.J. Henley, J.L. Hironaka, L. Guillou, M.A. Buchheim, J.A. Buchheim, M.W. Fawley, K.P. Fawley, Phylogenetic analysis of the "Nannochloris-like" algae and diagnoses of Picochlorum oklahomensis gen. et sp. nov. (Trebouxiophyceae, Chlorophyta), Phycologia 43 (2004) 641-652, https://doi.org/10.2216/i00318884-43-6-641.1.

[44] M. Krasovec, E. Vancaester, S. Rombauts, F. Bucchini, S. Yau, C. Hemon, H. Lebredonchel, N. Grimsley, H. Moreau, S. Sanchez-Brosseau, K. Vandepoele, G. Piganeau, Clues on thermotolerance unearthed in genomic analyses of the microalga, picochlorum costavermella (trebouxiophyceae), Genome Biol. Evol. (2018), https://doi.org/10.1093/gbe/evy167.

[45] F. Foflonker, G. Ananyev, H. Qiu, A. Morrison, B. Palenik, G.C. Dismukes, D. Bhattacharya, The unexpected extremophile: tolerance to fluctuating salinity in the green alga Picochlorum, Algal Res. 16 (2016) 465-472, https://doi.org/10. 1016/j.algal.2016.04.003.

[46] F. Foflonker, D.C. Price, H. Qiu, B. Palenik, S. Wang, D. Bhattacharya, Genome of the halotolerant green alga Picochlorum sp. reveals strategies for thriving under fluctuating environmental conditions, Environ. Microbiol. 17 (2015) 412-426, https://doi.org/10.1111/1462-2920.12541.

[47] C.R. Gonzalez-Esquer, S.N. Twary, B.T. Hovde, S.R. Starkenburg, Nuclear, chloroplast, and mitochondrial genome sequences of the prospective microalgal biofue strain picochlorum soloecismus, Genome Announc. 6 (2018) e01498, https://doi. org/10.1128/genomeA.01498-17.

[48] C.K. Black, D.M. Mihai, I. Washington, The photosynthetic eukaryote nannochloris eukaryotum as an intracellular machine to control and expand functionality of human cells, Nano Lett. 14 (2014) 2720-2725, https://doi.org/10.1021/ nl500655h.

[49] S. Wang, X. Shi, B. Palenik, Characterization of picochlorum sp use of wastewater generated from hydrothermal liquefaction as a nitrogen source, Algal Res. 13 (2016) 311-317, https://doi.org/10.1016/j.algal.2015.11.015.

[50] T.-Y. Chen, H.-Y. Lin, C.-C. Lin, C.-K. Lu, Y.-M. Chen, Picochlorum as an alternative to Nannochloropsis for grouper larval rearing, Aquaculture 338-341 (2012) 82-88, https://doi.org/10.1016/j.aquaculture.2012.01.011.

[51] K. Watanabe, K. Fujii, Isolation of high-level-CO2-preferring Picochlorum sp. strains and their biotechnological potential, Algal Res. 18 (2016) 135-143, https://doi. org/10.1016/j.algal.2016.06.013.

[52] M. de la Vega, E. Díaz, M. Vila, R. León, Isolation of a new strain of Picochlorum sp and characterization of its potential biotechnological applications, Biotechnol. Prog. 27 (2011) 1535-1543, https://doi.org/10.1002/btpr.686.

[53] D. Vaulot, F. Le Gall, D. Marie, L. Guillou, F. Partensky, The Roscoff Culture Collection (RCC): a collection dedicated to marine picoplankton, Nova Hedwigia 79 (2004) 49-70, https://doi.org/10.1127/0029-5035/2004/0079-0049.

[54] B. Winnepenninckx, T. Backeljau, R. De Wachter, Extraction of high molecular weight DNA from molluscs, Trends Genet. TIG. 9 (1993) 407.

[55] H. Li, R. Durbin, Fast and accurate long-read alignment with burrows-wheeler transform, Bioinformatics 26 (2010) 589-595, https://doi.org/10.1093/ bioinformatics/btp698.

[56] H. Li, B. Handsaker, A. Wysoker, T. Fennell, J. Ruan, N. Homer, G. Marth, G. Abecasis, R. Durbin, 1000 genome project data processing subgroup, the sequence alignment/map format and SAMtools, Bioinforma. Oxf. Engl. 25 (2009) 2078-2079, https://doi.org/10.1093/bioinformatics/btp352.

[57] M.A. Depristo, E. Banks, R. Poplin, K.V. Garimella, J.R. Maguire, C. Hartl, A.A. Philippakis, G. del Angel, M.A. Rivas, M. Hanna, A. McKenna, T.J. Fennell, A.M. Kernytsky, A.Y. Sivachenko, K. Cibulskis, S.B. Gabriel, D. Altshuler, M.J. Daly, A framework for variation discovery and genotyping using next-generation DNA sequencing data, Nat. Genet. 43 (2011) 491-498, https://doi.org/10.1038/ng.806.

[58] P. Cingolani, A. Platts, L.L. Wang, M. Coon, T. Nguyen, L. Wang, S.J. Land, X. Lu, D.M. Ruden, A program for annotating and predicting the effects of single nucleotide polymorphisms, SnpEff, Fly (Austin) 6 (2012) 80-92, https://doi.org/10. 4161/fly. 19695.

[59] L. Sterck, K. Billiau, T. Abeel, P. Rouzé, Y. van de Peer, ORCAE: online resource for community annotation of eukaryotes, Nat. Methods 9 (2012) 1041, https://doi.org/ 10.1038/nmeth. 2242 .

[60] A. Dobin, C.A. Davis, F. Schlesinger, J. Drenkow, C. Zaleski, S. Jha, P. Batut, M. Chaisson, T.R. Gingeras, STAR: ultrafast universal RNA-seq aligner, Bioinform. Oxf. Engl. 29 (2013) 15-21, https://doi.org/10.1093/bioinformatics/bts635.

[61] N. Sueoka, On the genetic basis of variation and heterogeneity of DNA base composition, Proc. Natl. Acad. Sci. U. S. A. 48 (1962) 582-592.

[62] S. Uphoff, N.D. Lord, B. Okumus, L. Potvin-Trottier, D.J. Sherratt, J. Paulsson, Stochastic activation of a DNA damage response causes cell-to-cell mutation rate variation, Science 351 (2016) 1094-1097, https://doi.org/10.1126/science. aac9786.

[63] D.L. Halligan, P.D. Keightley, Spontaneous mutation accumulation studies in evolutionary genetics, Annu. Rev. Ecol. Evol. Syst. 40 (2009) 151-172, https://doi.org/ 10.1146/annurev.ecolsys.39.110707.173437.

[64] M.G. Behringer, D.W. Hall, The repeatability of genome-wide mutation rate and spectrum estimates, Curr. Genet. (2016) 1-6, https://doi.org/10.1007/s00294-016 0573-7. 
[65] M. Lynch, W. Sung, K. Morris, N. Coffey, C.R. Landry, E.B. Dopman, W.J. Dickinson, K. Okamoto, S. Kulkarni, D.L. Hartl, W.K. Thomas, A genome-wide view of the spectrum of spontaneous mutations in yeast, Proc. Natl. Acad. Sci. U. S. A. 105 (2008) 9272-9277, https://doi.org/10.1073/pnas.0803466105.

[66] H. Long, M.G. Behringer, E. Williams, R. Te, M. Lynch, Similar mutation rates but highly diverse mutation spectra in ascomycete and basidiomycete yeasts, Genome Biol. Evol. 8 (2016) 3815-3821, https://doi.org/10.1093/gbe/evw286.

[67] W. Sung, A.E. Tucker, T.G. Doak, E. Choi, W.K. Thomas, M. Lynch, Extraordinary genome stability in the ciliate Paramecium tetraurelia, Proc. Natl. Acad. Sci. U. S. A. 109 (2012) 19339-19344, https://doi.org/10.1073/pnas.1210663109.

[68] G. Saxer, P. Havlak, S.A. Fox, M.A. Quance, S. Gupta, Y. Fofanov, J.E. Strassmann, D.C. Queller, Whole genome sequencing of mutation accumulation lines reveals a low mutation rate in the social amoeba Dictyostelium discoideum, PLoS One 7 (2012) e46759, , https://doi.org/10.1371/journal.pone.0046759.

[69] H. Long, D.J. Winter, A.Y.-C. Chang, W. Sung, S.H. Wu, M. Balboa, R.B.R. Azevedo, R.A. Cartwright, M. Lynch, R.A. Zufall, Low base-substitution mutation rate in the germline genome of the ciliate Tetrahymena thermophila, Genome Biol. Evol. (2016) evw223, https://doi.org/10.1093/gbe/evw223.

[70] H. Mao, H. Wang, S. Liu, Z. Li, X. Yang, J. Yan, J. Li, L.-S.P. Tran, F. Qin, A transposable element in a NAC gene is associated with drought tolerance in maize seedlings, Nat. Commun. 6 (2015) 8326, https://doi.org/10.1038/ncomms9326.

[71] W. Sung, M.S. Ackerman, S.F. Miller, T.G. Doak, M. Lynch, Drift-barrier hypothesis and mutation-rate evolution, Proc. Natl. Acad. Sci. 109 (2012) 18488-18492, https://doi.org/10.1073/pnas.1216223109.

[72] I.K. Blaby, B.J. Lyons, E. Wroclawska-Hughes, G.C.F. Phillips, T.P. Pyle,
S.G. Chamberlin, S.A. Benner, T.J. Lyons, V. de Crécy-Lagard, E. de Crécy, Experimental evolution of a facultative thermophile from a mesophilic ancestor, Appl. Environ. Microbiol. 78 (2012) 144-155, https://doi.org/10.1128/AEM. 05773-11.

[73] R.A. LaCroix, B.O. Palsson, A.M. Feist, A model for designing adaptive laboratory evolution experiments, Appl. Environ. Microbiol. 83 (2017) e03115-e03116, https://doi.org/10.1128/AEM.03115-16.

[74] M.-M. Perrineau, J. Gross, E. Zelzion, D.C. Price, O. Levitan, J. Boyd, D. Bhattacharya, Using natural selection to explore the adaptive potential of chlamydomonas reinhardtii, PLoS One 9 (2014) e92533, , https://doi.org/10.1371/ journal.pone.0092533.

[75] D. Marie, F. Le Gall, R. Edern, P. Gourvil, D. Vaulot, Improvement of phytoplankton culture isolation using single cell sorting by flow cytometry, J. Phycol. (2016), https://doi.org/10.1111/jpy.12495.

[76] J. Rumin, H. Bonnefond, B. Saint-Jean, C. Rouxel, A. Sciandra, O. Bernard, J.P. Cadoret, G. Bougaran, The use of fluorescent Nile red and BODIPY for lipid measurement in microalgae, Biotechnol. Biofuels. 8 (2015) 42, https://doi.org/10. 1186/s13068-015-0220-4.

[77] B. Guo, C. Lei, T. Ito, Y. Jiang, Y. Ozeki, K. Goda, High-throughput accurate singlecell screening of Euglena gracilis with fluorescence-assisted optofluidic time-stretch microscopy, PLoS One 11 (2016) e0166214, , https://doi.org/10.1371/journal. pone.0166214.

[78] C.M. Yousuff, E.T.W. Ho, I. Hussain, N.H.B. Hamid, Microfluidic platform for cell isolation and manipulation based on cell properties, Micromachines 8 (2017) 15, https://doi.org/10.3390/mi8010015. 